\title{
The emergence of chloroquine-sensitive Plasmodium falciparum is influenced by selected communities in some parts of the Central Region of Ghana
}

\author{
Kwame Kumi Asare ${ }^{1^{*}} \mathbb{0}$, Justice Africa ${ }^{2}$, Jennifer Mbata ${ }^{3}$ and Yeboah Kwaku Opoku ${ }^{3}$
}

\begin{abstract}
Background: The return of chloroquine-sensitive Plasmodium falciparum in sub-Saharan Africa countries offers the opportunity for the reintroduction of chloroquine (CQ) either in combination with other drugs or as a single therapy for the management of malaria. This study assesses the influence of individual study sites on the selection of CQ sensitive $P$. falciparum markers in the Central region of Ghana.

Methods: Genomic DNA was extracted from an archived filter paper blood blot from Cape Coast, Elmina, Assin Fosu, and Twifo Praso using the Chelex DNA extraction method. The age metadata of the patients from whom the blood spots were taken was collected. The prevalence of CQ-sensitive markers of pfcrt K76 and pfmdr 1 N86 was performed using nested PCR and RFLP. The data were analysed using Chi-square and Odd ratio.

Results: The overall prevalence of CQ-sensitive P. falciparum markers, pfcrt K76 and pfmdr1 N86 in the Central Region of Ghana were 142 out of 184 (77.17\%) and 180 out of 184 (97.83\%), respectively. The distribution of pfcrt K76 was assessed among the age groups per the individual study sites. 12 out of 33 (36.36\%), 8 out of 33 (24.24\%) and 6 out of $33(18.18 \%)$ of pfcrt K76 CQ-sensitive marker were isolated from age 0 to 5 years, 16 to 30 years and 31 to 45 years old respectively at Cape Coast. Assin Fosu and Twifo Praso had the highest pfcrt K76 prevalence in 0-5 years, followed by 16-30 years and 6-15 years of age. The results showed that there was a significant prevalence of pfcrt K76 in all study sites; Cape Coast $\left(x^{2}=26.48, p<0.0001\right)$, Assin Fosu $\left(x^{2}=37.67, p<0.0001\right)$, Twifo Praso $\left(x^{2}=32.25, p<0.0001\right)$ and Elmina $\left(x^{2}=17.88, p<0.0001\right)$. Again, the likelihood to detect pfcrt K76 (OR (95\% Cl) was 7.105 (3.118-17.14), $p<0.0001$ and pfmdr1 (2.028 (1.065-3.790), $p<0.001)$ among P. falciparum isolates from Cape Coast to be seven times and two times, respectively.

Conclusion: The study showed a significant selection and expansion of chloroquine-sensitive P. falciparum markers in all the selected study areas in the Central region. This finding has a significant implication for the future treatment, management, and control of P. falciparum malaria.
\end{abstract}

\footnotetext{
*Correspondence: kwame.asare@ucc.edu.gh; kwamsare@hotmail.com;

kwamsare@yahoo.com

${ }^{1}$ Department of Biomedical Sciences, School of Allied Health Sciences,

College of Health and Allied Sciences, University of Cape Coast, Cape

Coast, Ghana

Full list of author information is available at the end of the article
}

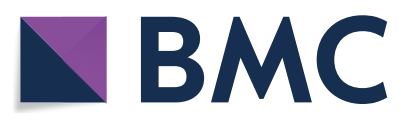

(c) The Author(s) 2021. Open Access This article is licensed under a Creative Commons Attribution 4.0 International License, which permits use, sharing, adaptation, distribution and reproduction in any medium or format, as long as you give appropriate credit to the original author(s) and the source, provide a link to the Creative Commons licence, and indicate if changes were made. The images or other third party material in this article are included in the article's Creative Commons licence, unless indicated otherwise in a credit line to the material. If material is not included in the article's Creative Commons licence and your intended use is not permitted by statutory regulation or exceeds the permitted use, you will need to obtain permission directly from the copyright holder. To view a copy of this licence, visit http://creativecommons.org/licenses/by/4.0/. The Creative Commons Public Domain Dedication waiver (http://creativeco mmons.org/publicdomain/zero/1.0/) applies to the data made available in this article, unless otherwise stated in a credit line to the data. 
Keywords: Plasmodium falciparum, Chloroquine-resistance parasites, Chloroquine-sensitive parasites, Pfcrt, Pfmdr1, Central Region, Ghana

\section{Background}

The return of chloroquine (CQ) sensitive Plasmodium falciparum in sub-Saharan Africa is associated with increased prevalence of wildtype $p f c r t$ and $p f m d r 1$ variants $[1,2]$. Until the emergence of $P$. falciparum resistance to $C Q$ and its subsequent withdrawal, CQ was widely used for self-medication for suspected malaria cases [3]. CQ has resistance hampered malaria control and contributed to high mortality especially among children in sub-Saharan Africa $[4,5]$. The re-emergence of CQ-sensitive $P$. falciparum parasites offers the opportunity to introduce this drug either in combination therapy or as a single anti-malarial drug [6-9]. Although the reappearance of CQ-sensitive parasites has been observed in all countries, the rate of re-emergence varies from place to place [10-12]. The central region of Ghana has experienced a slow appearance of CQ-sensitive $P$. falciparum compared to other parts of the country $[13,14]$. The slow appearance of CQ-sensitive $P$. falciparum in the Central region has been attributed to the continuous usage of $C Q$ in some parts of the Central region [13]. Early CQ treatment failure and worsening malaria conditions in young children have been reported to be higher in Tanzania, Uganda, Zambia, and Ecuador compared to Ghana [15]. Malaria prevalence has remained high while malariarelated mortality has remained stable in 5-15 years old but decreased in $0-5$ years of age [16]. The withdrawal of chloroquine and introduction of artemisinin-based combination therapy (ACT) has resulted in the re-emergence of CQ-sensitive markers.

The P. falciparum pfcrt K76T and pfmdr1 N86Y resistant markers are well established to be responsible for chloroquine resistance globally [17]. In Ghana, the prevalence of $p f c r t \mathrm{~K} 76 \mathrm{~T}$ and $p f m d r 1 \mathrm{~N} 86 \mathrm{Y}$ varies from one place to another $[14,18-25]$. The pfcrt K76T (11\%) and pfmdr1 N86Y (8.1\%) respectively have been reported as the prevalence of the CQ-resistant parasite in the Greater Accra region of Ghana in 2018 [18]. In Cape Coast, pfcrt K76T prevalence has gradually decrease from 47 to $53.7 \%$ in $2014,38 \%$ in $2015,29 \%$ in 2016 and $29 \%$ in 2017 whiles pfmdr1 N86Y prevalence were $18-36 \%$ in 2014, $18 \%$ in $2015,5 \%$ in 2016 and $5 \%$ in 2017 [12, 14, 19]. This is good news as CQ anti-malarial drugs could be used as a stopgap to salvage the current challenges involved in the emerging artemisinin resistance. Currently, no new anti-malarial drugs or effective malaria vaccine is available for malaria treatment [23, 24]. The increasing ACT treatment failure requires the reintroduction of $\mathrm{CQ}$ combination be considered as an option whiles wait for new and effective anti-malarials and vaccines [25].

Artesunate-amodiaquine (ASAQ), artemether-lumefantrine (AL), and dihydroartemisinin-piperaquine (DHAP) are the first-line anti-malarial drugs for the management of uncomplicated malaria in Ghana [26]. However, the emergence of artemisinin resistance in $P$. falciparum in South-East Asia and Rwanda has led to treatment failure of ACT [27, 28]. A current survey from 2007 to 2016 using archived blood samples from Ghana had shown that $p f k 13$ mutations responsible for both Asian and African artemisinin resistance were prevalent in Ghanaian P. falciparum parasites [29]. The study also frequently identified N599Y, K607E, and V637G non-synonymous mutations in the samples [29]. This indicates that the Ghanaian P. falciparum parasites can develop resistance to artemisinin [29, 30]. Therefore, the return of CQ-sensitive parasites in the country is essential as CQ combinations can be reintroduced should artemisinin treatment completely fail.

The continuous usage of CQ has been associated with the slow recovery of CQ sensitive parasites in some parts of Ghana $[13,18,19]$. The previous study showed that the proscribed usage of CQ was very important for maintaining CQ resistant markers in Central Region [13]. The report of increasing $C Q$ sensitive markers in the region is good news, however, the prevalence of these markers is relatively low in the Central region compared to other parts of Ghana. The factors influencing the variations in the selection and emergence of CQ sensitive markers in the different malaria-endemic areas are not well understood. The study, therefore, aimed to assess the effects of the various study sites parameters on the prevalence of CQ-sensitive $P$. falciparum parasites in the Central Region of Ghana.

\section{Methods}

\section{Study sites}

The study was conducted in four districts in the Central Region of Ghana. The samples were selected from two ecological zones with different malaria endemicity. Assin Fosu and Twifo Praso in the forest zone have a high $P$. falciparum malaria prevalence compared to Cape Coast and Elmina in the coastal zone which has lower malaria prevalence in the Central Region of Ghana. The Cape Coast metropolis which is the smallest metropolis in Ghana covers an area of 122 square km and is bounded to the West by Komenda/Edina/Eguafo/ 
Abrem Municipality. The Gulf of Guinea is located in the southern part of the Metropolis with Abura/Asebu/Kwamankese covering the eastern boundary. It also shares its northern boundary with Twifu/Hemang/Lower Denkyira District. Cape Coast is also the Central Regional Capital of Ghana. Elmina is the district capital of the KomendaEdina-Eguafo-Abirem (KEEA) district. The KEEA covers an area of 1372.45 square kilometres (919.95 square miles) and lies between longitude $1^{\circ} 20^{\circ}$ West and $1^{\circ} 40^{\circ}$ West and latitude $5^{\circ} 05^{\circ}$ North and $5^{\circ}$ North $15^{\circ}$ North. The eastern and North-Eastern bothers of KEEA are Cape Coast Metropolis and Twifo-Heman Lower Denkyira districts respectively. Twifo-Praso is located in the Twifo/Heman/Lower Denkyira district and also serves as its district capital. The total area covered by the district extends to about 1199 square kilometres and lies within latitudes $5^{\circ} 50^{\circ} \mathrm{N}$ and $5^{\circ} 51^{\circ} \mathrm{N}$ and longitudes $1^{\circ} 50^{\circ} \mathrm{W}$ and $1^{\circ} 10^{\circ} \mathrm{W}$ with about 1510 settlements. Finally, the Assin North municipality is made up of about 1000 settlements. Major among them include Assin Fosu, Assin Akonfudi, Assin Kushea, Assin Praso, etc. The Municipal lies within longitudes $1^{\circ} 05^{\circ}$ East and $1^{\circ} 25^{\circ}$ West and latitudes $6^{\circ} 05^{\circ}$ North and $6^{\circ} 40^{\circ}$ South with a land coverage of about 1500 square kilometres. It is bounded by upper Dankyira, Ajumako Enyan-Esiam, Assin South Districts as well as lower Dankyira (Fig. 1) [13, 19].

\section{Sample collection}

The sample size, 214, was calculated using the following method as described; $n=z^{2} p q / d 2$, where $n=$ the desired sample size (when the population is greater than $10,000) ; \mathrm{z}=$ the standard normal deviation, usually set at 1.96 , which corresponds to the $95 \%$ confidence interval; $\mathrm{p}=$ the proportion in the target population estimated to have a particular characteristic(s); If there is no reasonable estimate, then $50 \%$ is used; $q=1.0-p ; d=$ degree of accuracy desired, usually set at 0.05 level or occasionally at 0.02 . Each selected site has a population greater than 10,000 . The standard deviation $(\mathrm{z})$ was set at 1.96 , which corresponds to the $95 \%$ confidence level. The pfcrt $\mathrm{K} 76$ prevalence among malaria isolates in Ghana (88.4\%) [31] was used as the proportion in the target

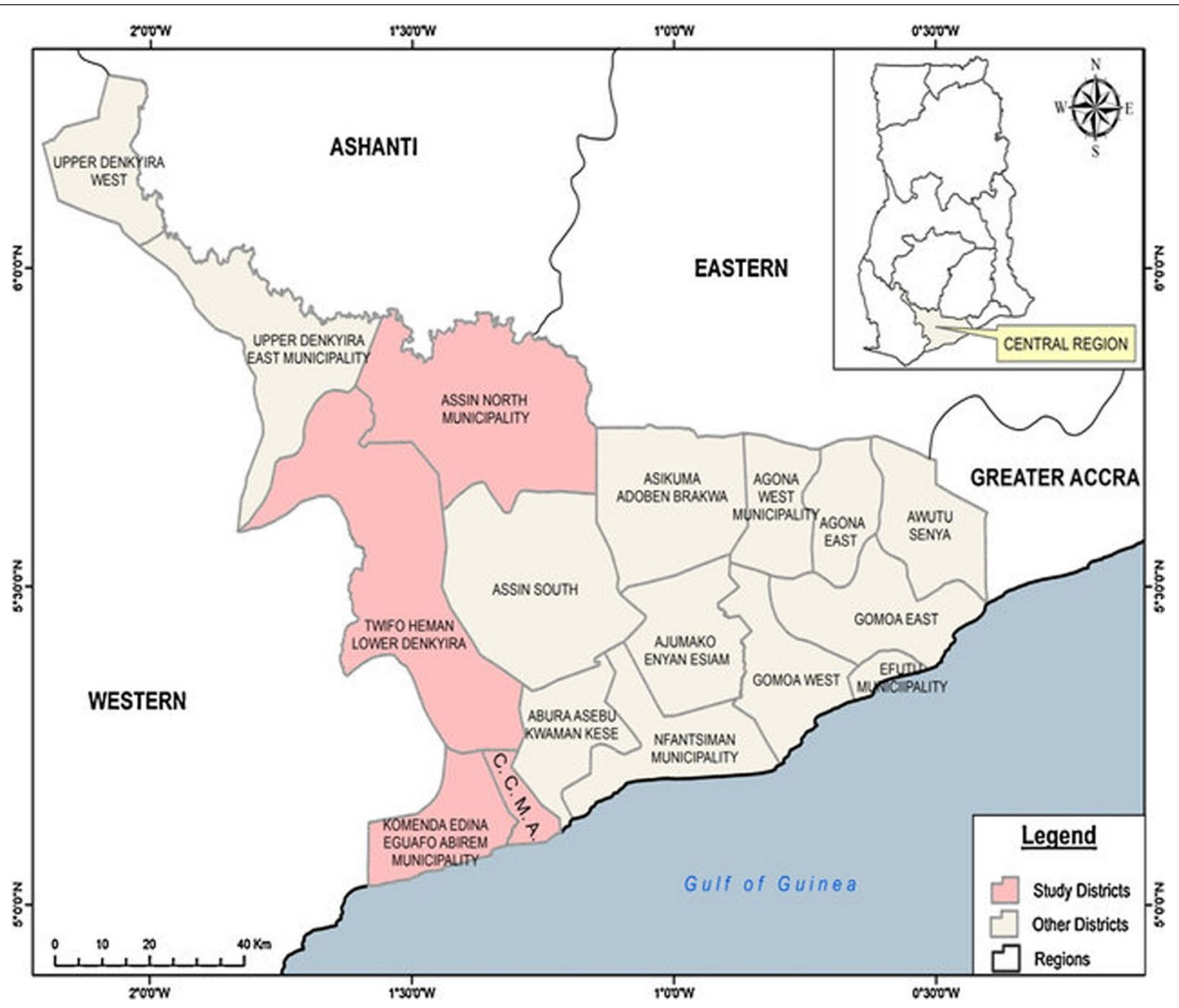

Fig. 1 Map of the Central Region of Ghana. Map showing the district where the study was conducted 
population estimated to have a particular characteristic (which, in this case, is malaria) (p). Therefore $\mathrm{p}=0.884$, and $\mathrm{q}=1-0.884=0.116$. The degree of accuracy was set at 0.05 . Hence $\mathrm{n}=\mathrm{z}^{2} \mathrm{pq} / \mathrm{d} 2 \mathrm{n}=(1.962)(0.884)(0.116) /$ (0.052), $\mathrm{n}=0.39393 / 0.0025, \mathrm{n}=157.57$. However, $214 P$. falciparum parasites were analysed from the four study sites $[19,20]$.

Archived P. falciparum-infected blood blot samples (214) previously successful extracted from Cape Coast, Elmina, Twifo Praso, and Assin Fosu collected between April 2012 and December 2013 were used for this study $[19,31]$. The air-dried blood spots in zip-locked plastic envelopes containing silica gel stored at $-20{ }^{\circ} \mathrm{C}$ freezer in the Department of Biomedical Sciences, University of Cape Coast were extracted using the chelex extraction method $[19,31]$. The excel data which contains the sample numbers and patient information at the Department were obtained for the analysis (Additional file 1: Fig. 1).

\section{Genomic DNA extraction}

The Chelex-saponin DNA extraction method was used [13]. Briefly, discs punched of about $2.5 \mathrm{~mm}(2 \times)$ were made from the dried blood spot then transferred into a $1.5 \mathrm{~mL}$ Eppendorf tube. $50 \mu \mathrm{L}$ of $10 \%$ saponin and $1 \mathrm{~mL}$ of $1 \times$ PBS were added to the blood spots in $1.5 \mathrm{~mL}$ tubes. The sample and saponin mixture was vortexed and frozen at $4{ }^{\circ} \mathrm{C}$ overnight. The filter was washed $3 \times$ with $1 \mathrm{~mL}$ of $1 \times$ PBS, followed by $30 \mu \mathrm{L}$ of $20 \%$ chelex and $70 \mu \mathrm{L}$ of DNase/RNase water. The sample was incubated at 95 ${ }^{\circ} \mathrm{C}$ for $10 \mathrm{~min}$ with intermittent vortexing. The genomic DNA (gDNA) samples were eluted from the filter by centrifuging at 13,000 rpm for $6 \mathrm{~min}$ and the supernatant was transferred into a sterile $0.5 \mathrm{~mL}$ microfuge tube. The extracted gDNA was stored at $-20^{\circ} \mathrm{C} .[13,19,31]$

\section{Amplification of pfcrt and pfmdr 1 by nested polymerase chain reaction (PCR)}

The genomic DNA of $P$. falciparum was amplified using primer pairs (P10-1forw: TTGTCGACCTTAACAGAT GGCTCAC/P10-1 rev: AATTTCCCTTTTTATTTC CAAATAAGGA for $p f c r t \&$ P1-1 forw: TTAAATGTT TACCTGCACAACATAGAAATT/P1-1 rev: CTCCAC AATAACTTGCAACAGTTCTTA for mdr1, primary reaction and P10 forw: CTTGTCTTGGTAAATGTG CTC/P10 rev: GAACATAATCATACAAATAAAGT for pfcrt \& P1 forw: TGTATGTGCTGTATTATCAGGA/P1 rev: CTCTTCTATAATGGACATGGTA for secondary reaction). The primary PCR reaction mixture contained $0.2 \mu \mathrm{M}$ of the primary primer pair, $5 \mu \mathrm{L}$ DNA template, $1 \times$ PCR buffer, $200 \mu \mathrm{M} \mathrm{dNTPs,} 1.5 \mathrm{mM} \mathrm{MgCl}_{2}$, and 1.25 $\mathrm{U}$ of Taq DNA Polymerase in a $25 \mu \mathrm{L}$ mixture. The PCR cycling conditions $\left(95^{\circ} \mathrm{C}\right.$ for the $30 \mathrm{~s},\left[95^{\circ} \mathrm{C}\right.$ for $15 \mathrm{~s}$, $53{ }^{\circ} \mathrm{C}$ for $1 \mathrm{~min}, 68{ }^{\circ} \mathrm{C}$ for $1 \mathrm{~min}$ ], $68{ }^{\circ} \mathrm{C}$ for $5 \mathrm{~min}$ final extension). The secondary PCR was performed using 0.5 $\mu \mathrm{L}$ of the primary PCR reaction and $133.33 \mathrm{nM}$ each of the second primer pairs. The PCR cycling condition was the same except for the annealing temperature which was $60{ }^{\circ} \mathrm{C}$ for the second PCR. The secondary PCR products $(1 \mu \mathrm{L})$ were run on a $2 \%$ agarose gel and visualized using a CSL gel documentation system (CSL, UK) (Additional file 2).

Restriction fragment length polymorphism (RFLP) $[13,32]$ The nested PCR products of $p f c r t$ were digested with Apo I whereas that of Pfmdr1 were digested with Apo I and Afl III. The digested products $(5 \mu \mathrm{L})$ were separated on $2 \%$ electrophoresis gel, stained with ethidium bromide, and viewed under ultraviolet light. The $p f c r t$ PCR product contains a single Apo I site if the codon 76 of the pfcrt gene encodes for lysine (K76). For pfmdr1, codon 86 was digested with both Apo I for asparagine and Afl III to confirm the tyrosine mutation at position 86 in all the $p f m d r 1$ samples that were not digested by Apo I. The digested samples were run on $2 \%$ agarose gel and visualized using a CSL gel documentation system.

\section{Data analysis}

The data from RFLP analysis, patient ages \& sample collection sites were organized using Microsoft Office Excel 2010 (Microsoft Corporation) and the statistical analyses were performed with GraphPad Prism software, version 8.4.3 (GraphPad Software). All mixed alleles infection of wild type and resistant strains of pfcrt K76T and pfmdr1 N86Y (Cape coast: $n=6 / 46$ (13.04\%), Elmina: $n=8 / 39$ (20.15\%), Twifo Praso: $\mathrm{n}=8 / 60$ (13.33\%) and Assin Fosu $n=8 / 69(11.59 \%)$ ) were excluded from the analysis because these could not be classified as solely resistant or CQ-sensitive parasites. The ages of the patients were categorized into $0-5$ years, $6-15$ years, $16-30$ years, $31-45$ years \& above 45 years for the analysis. The statistical significance was determined using $2 \times 2$ contingency Chi-square and odds ratio. A p-value $<0.05$ was considered statistical significance.

\section{Results}

The overall prevalence of CQ-sensitive $P$. falciparum markers, $p f c r t$ K76 and pfmdr1 N86 in the Central Region of Ghana were 142 out of 184 (77.17\%) and 180 out of 184 (97.83\%), respectively. Assin Fosu harboured the highest number of $P$. falciparum expressing CQ-sensitive pfcrt K76 marker 45 out of 142 (31.69\%) followed by Twifo Praso 40 out of 142 (28.17\%) samples analysed. A similar observation was made for the $p f m d r 1$ N86 CQ-sensitive gene (Fig. 2). 33 (82.5\%), 45 (73.77\%), 40 (76.92\%) and $24(97.83 \%)$ were the prevalences of pfcrt $\mathrm{K} 76$ and 29 (63.04\%), 61 (88.40\%), 54 (90.00\%) and 36 (92.30\%) 


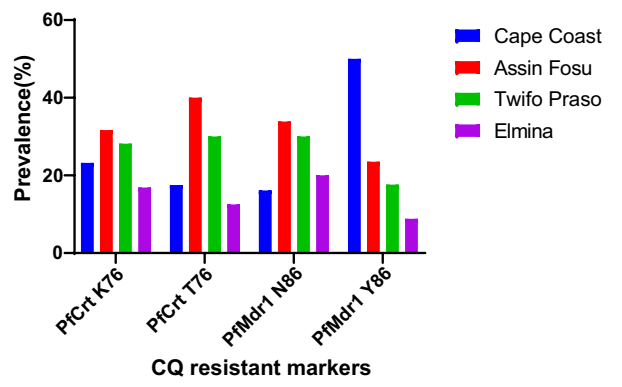

Fig. 2 The prevalence of chloroquine sensitive and resistance markers pfcrt K76T and pfmdr 1 N86Y at the study sites

were the prevalence of $p f m d r 1$ N86 at Cape Coast, Assin Fosu, Twifo Praso and Elmina study sites, respectively (Table 1).

The distribution of pfcrt K76 was assessed among the age groups for the individual study sites. 12 out of 33 (36.36\%), 8 out of $33(24.24 \%)$ and 6 out of $33(18.18 \%)$ of pfcrt K76 CQ-sensitive markers were isolated from age $0-5$ years, $16-30$ years and $31-45$ years old respectively at Cape Coast. Assin Fosu and Twifo Praso had the highest pfcrt $\mathrm{K} 76$ prevalence in $0-5$ years, followed by 16-30 years and 6-15 years of age. However, the highest prevalence of pfcrt K76 was observed among subjects between the age group 16-30 years, followed by $31-45$ years and above 45 years of age at the Elmina study site (Fig. 3). Similar observations were made for $p f m d r 1$ N86 CQ-sensitive markers at each of the individual study sites with Assin Fosu having the highest pfmdr1 prevalence in 23 out of 61 (37.70\%) in 0-5 years followed by 22 out of 61 (36.07\%) in 16-30 years of age (Fig. 4).

To determine the influence of study sites on the prevalence of CQ-sensitive markers pfcrt K76 and pfmdr1 N86, an association study was conducted. The result should that there is a significant prevalence of pfcrt $\mathrm{K} 76$ in all study sites; Cape Coast $\left(x^{2}=26.48, p<0.0001\right)$, Assin Fosu $\left(x^{2}=37.67, p<0.0001\right)$, Twifo Praso $\left(x^{2}=32.25\right.$,

Table 1 Prevalence of pfcrt K76T and pfmdr1 N86Y at the study sites

\begin{tabular}{llllll}
\hline Study sites & \multicolumn{2}{l}{ Pfcrt 76 n/N(\%) } & & \multicolumn{2}{l}{ Pfmdr1 86 n/N (\%) } \\
\cline { 2 - 3 } \cline { 5 - 6 } & $\mathbf{K}$ & $\mathbf{T}$ & & $\mathbf{N}$ & $\mathbf{Y}$ \\
\hline Cape Coast & $33 / 40$ & $7 / 40(17.5 \%)$ & & $29 / 46$ & $17 / 46$ \\
& $(82.5 \%)$ & & & $(63.04 \%)$ & $(36.96 \%)$ \\
Assin Fosu & $45 / 61$ & $16 / 61$ & & $61 / 69$ & $8 / 69(11.60 \%)$ \\
& $(73.77 \%)$ & $(26.23 \%)$ & & $(88.40 \%)$ & \\
Twifo Praso & $40 / 52$ & $12 / 52$ & & $54 / 60$ & $6 / 60(10.00 \%)$ \\
Elmina & $(76.92 \%)$ & $(23.08 \%)$ & & $(90.00 \%)$ & \\
& $24 / 29$ & $5 / 29$ & & $36 / 39$ & $3 / 39(7.69 \%)$ \\
& $(82.76 \%)$ & $(17.24 \%)$ & & $(92.3 \%)$ & \\
\hline
\end{tabular}

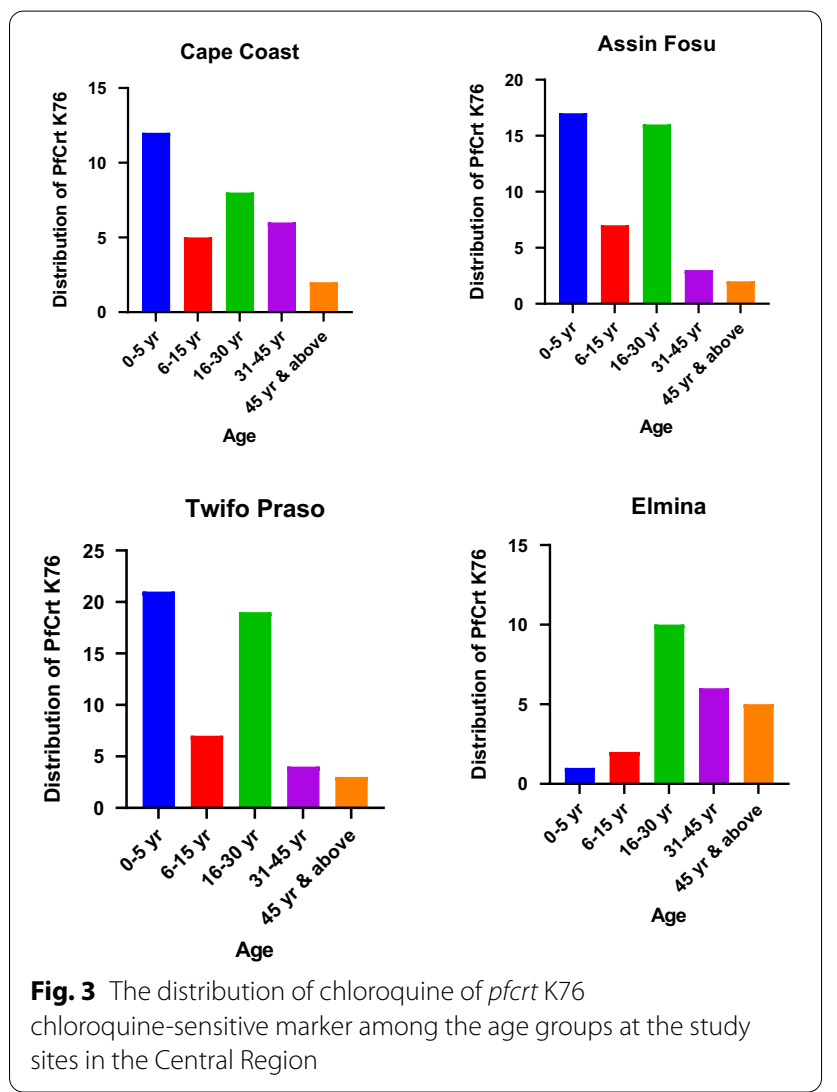

$\mathrm{p}<0.0001)$ and Elmina $\left(\mathrm{x}^{2}=17.88, \mathrm{p}<0.0001\right)$. Similar observations were made for the prevalence of $p f m d r 1$ N86 CQ-resistant marker at Cape Coast $\left(X^{2}=4.977\right.$, $\mathrm{p}=0.0257)$, Assin Fosu $\left(x^{2}=42.94, \mathrm{p}<0.0001\right)$, Twifo Praso $\left(\chi^{2}=51.75, \mathrm{p}<0.0001\right)$ and Elmina $\left(\chi^{2}=30.85\right.$, $\mathrm{p}<0.0001$ ) (Table 2).

The odds of detecting $P$. falciparum isolates harbouring CQ-sensitive pfcrt K76 and pfmdr1 N86 at each of the study sites were assessed. The results showed that there the odds for the detection of pfcrt K76 (OR (95\% CI) was 7.105 (3.118-17.14), $\mathrm{p}<0.0001$ and that of $p f m d r 1$ was 2 (2.028 (1.065-3.790), $\mathrm{p}<0.001)$ among P. falciparum isolates from Cape Coast. Assin Fosu had the highest likelihood for the detection of pfcrt K76, OR (95\% CI) 8.477 (3.926-17.83), $\mathrm{p}<0.0001$ and Elmina had the highest odd of the detection of $p f m d r 1$ N86 OR (95\% CI) 14.27 (4.795-44.67), $\mathrm{p}<0.0001$ among the $P$. falciparum isolates in Central Region of Ghana (Table 3).

\section{Discussion}

The recovery of the CQ-sensitive P. falciparum has come at a time when the treatment and management of malaria are constrained with the development of resistance to almost all the most effective anti-malarial drugs [32, 33]. Although the current advances and knowledge in malaria 
Table 2 Association the study sites and the prevalence of prevalence of Chloroquine sensitive markers

\begin{tabular}{|c|c|c|c|c|c|c|}
\hline \multirow[t]{2}{*}{ Town } & \multicolumn{3}{|c|}{ Pfcrt K76 } & \multicolumn{3}{|c|}{ Pfmdr1 N86 } \\
\hline & $x^{2}$ & z-test & $p$ & $\mathrm{x}^{2}$ & z-test & $p$ \\
\hline Cape coast & 26.48 & 5.145 & $<0.0001$ & 4.977 & 2.231 & 0.0257 \\
\hline Assin Fosu & 37.67 & 6.138 & $<0.0001$ & 42.94 & 6.553 & $<0.0001$ \\
\hline Twifo Praso & 32.25 & 5.679 & $<0.0001$ & 51.75 & 7.194 & $<0.0001$ \\
\hline Elmina & 17.88 & 4.228 & $<0.0001$ & 30.85 & 5.555 & $<0.0001$ \\
\hline
\end{tabular}

Table 3 The odds of detecting chloroquine-sensitive markers (pfcrt K76 and pfmdr 1 N86) among P. falciparum isolate at the study sites

\begin{tabular}{lccccc}
\hline Town & Pfcrt K76 & & & Pfmdr1 N86 \\
\cline { 2 - 3 } & Odd ratio (95\% Cl) & $\mathbf{p}$ & & Odd ratio (95\% Cl) & $\mathbf{p}$ \\
\hline Cape coast & $7.105(3.118-17.14)$ & $<0.0001$ & $2.028(1.065-3.790)$ & $<0.001$ \\
Assin Fosu & $8.477(3.926-17.83)$ & $<0.0001$ & & $9.065(4.206-18.96)$ & $<0.0001$ \\
Twifo Praso & $7.535(3.425-15.89)$ & $<0.0001$ & $13.56(5.972-29.93)$ & $<0.0001$ \\
Elmina & $5.177(2.367-11.15)$ & $<0.0001$ & $14.27(4.795-44.67)$ & $<0.0001$ \\
\hline
\end{tabular}

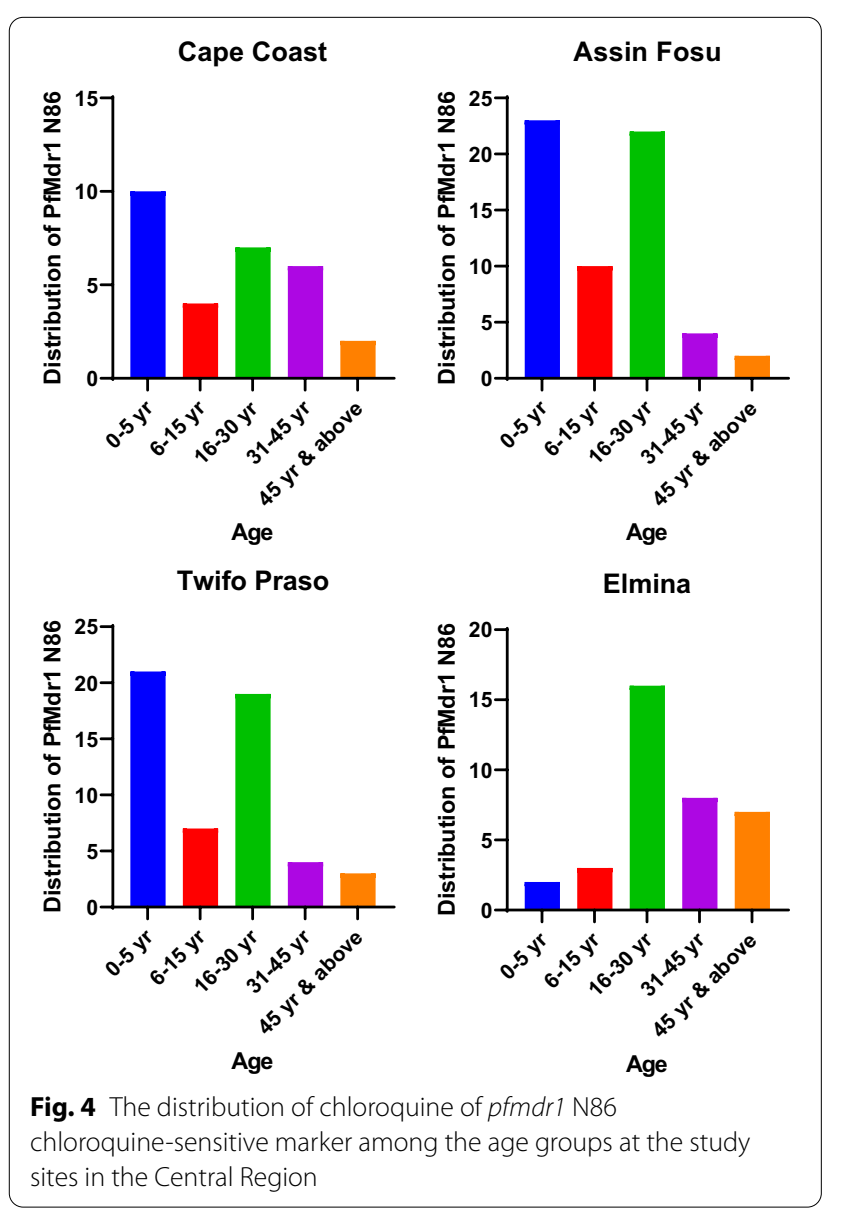

biology have the potential to identify drug targets for the development of safe, effective, and efficient anti-malarial drugs and vaccines for the management of malaria, they are yet to produce an effective means to tackle the challenges facing malaria treatment and management [34, 35]. As exploration for the new treatment strategies continues coupled with the identification of novel drug targets and the design of new anti-malarial compounds, it is important to understand the dynamism and factors that influence the re-emergence of CQ-sensitive $P$. falciparum in malaria-endemic areas [36, 37]. This will better position scientists in the implementation of appropriate protocols for the re-introduction of $C Q$ as a temporal strategy to control malaria as we wait for the new effective and safe anti-malarial drugs and vaccines [38]. This study focuses on assessing the effects of study sites on the prevalence and the emergence of CQ-sensitive markers, pfcrt K76 and pfmdr1 N86 alleles among P. falciparum isolate in the Central region of Ghana.

The study showed a reduction in CQ-resistant markers in the Central region of Ghana. A similar result has been reported in other parts of Ghana [12]. Although the steady decline of pfcrt T76 and pfmdr1 Y86 has been very slow from 62 to $89 \%$ between 2014 and 2017 especially at the regional capital (Cape Coast) of the Central region of Ghana compared to other places in Ghana, the expansion of the CQ-sensitive $P$. falciparum strains have increased appreciably $[14,19,31]$. Similar reports on the reappearance of CQ-sensitive parasites have been reported in Malawi, Cameroon, Ethiopia, Nigeria, Tanzania, and Mozambique [6, 10, 11,39-42]. The decrease in 
CQ-resistant markers and subsequent parasite sensitivity to CQ treatment have been demonstrated clinically [43]. The slow appearance of pfcrt K76 \& pfmdr1 N86 suggests that the maintenance of the integrity of CQ-resistant phenotypes has fitness costs in the absence of CQ drug pressure $[44,45]$. The absence of CQ drug pressure results in the negative selection of CQ-resistant parasites; thus, driving the evolution of CQ-sensitive parasites [45]. Thus, the reappearance of CQ-sensitive pfcrt K76 \& pfmdr1 N86 alleles has also been observed in malaria transmission.

Also, the recovery of $\mathrm{CQ}$-sensitive parasites is determined by eco-epidemiological factors such as migration and vector competence within an area. Thus, the expansion of pfcrt K76 \& pfmdr1 N86 observed among the study sites could be attributed to migration. A previous report indicated the possibility of $p f c r t$ sensitive parasites either upsurging from low levels in the indigenous parasite populations or migrating from bordering countries with persistent CQ drug pressure [46]. This observation supports the idea of migration of CQ-sensitive phenotype from places with persistent CQ pressure [1]. All the study sites were significantly associated with the prevalence of $p f c r t \mathrm{~K} 76$ and $p f m d r 1$ N86. The odds of detecting CQ-sensitive markers, pfcrt K76 was high at Assin Fosu, Twifo Praso and Cape Coast whereas odds of detecting CQ-sensitive markers, pfmdr1 N86 was high at Elmina, Twifo Praso and Assin Fosu. Such migration of pfcrt K76 \& pfmdr1 N86 alleles could be due to rapid movements of goods and services as well as human traffic among Cape Coast (the regional capital), Assin Fosu (Assin north municipal capital), and Twifo Praso (the district capital of Twifo Heman Lower Denkyira) cyclically. It has also been shown that transiting from malaria-endemic areas to hypoendemic areas exposes people to the changing risks of malaria infections $[47,48]$. Thus, the pattern of malaria infection within a community is significantly influenced by the movement of people [49]. The association of the prevalence of pfcrt K76 \& pfmdr1 N86 among the study areas take a similar pattern of the spread of drug resistance lineage parasites [50]. Thus, the continuous usage or complete withdrawal of $\mathrm{CQ}$ from an area determines the level of prevalence of CQ drug-resistant parasites within the area.

\section{Limitations}

The study used archived samples and therefore could not allow for assessment of critical factors such as immunity and migration which are very important in the evolution of drug-resistant alleles. The prevalence of drug-resistant $P$. falciparum are changing which require large quantities of field samples and the assessment of host factors, parasite factors and environmental factors need to be constantly updated to provide the current status of antimalarial drug resistance in the Central Region of Ghana.

\section{Conclusion}

The study has shown an association between study sites and the prevalence of CQ-sensitive markers with high odds for detecting pfcrt K76 and pfmdr1 N86 among $P$. falciparum isolates in the Central Region of Ghana. These findings have significant implications for the future treatment, management, and control of P. falciparum malaria.

\section{Supplementary Information}

The online version contains supplementary material available at https://doi. org/10.1186/s12936-021-03985-8.

Additional file 1: Figure 1. Restriction fragment length polymorphism for pfcrt 76 and pfmdr 186 alleles. (1) RFLP of pfcrt 76: Apo I digestion of pfcrt amplicons containing codon 76 polymorphism. Lane $\mathrm{M}$ is $100-1000 \mathrm{bp}$ molecular size marker, lane 1 is a known sample, and lanes 2-21 are $P$. falciparum isolates. The wild-type allele has amplicons $89 \mathrm{bp}$ and $123 \mathrm{bp}$ whiles the mutant-type allele has $200 \mathrm{bp}$ and mixed infection has three amplicons. (2) RFLP of pfmdr1 86: Afl III digestion of pfmdr 1 amplicons containing codon 86 polymorphism. Lane M is 100-1000 bp molecular size marker, lane 1 is a known sample, and lanes 2-21 are P. falciparum isolates. The mutant-type allele has two amplicons $200 \mathrm{bp}$ and $300 \mathrm{bp}$ amplicons compared to the wildtype with $240 \mathrm{bp}$ and $260 \mathrm{bp}$.

Additional file 2. Sections of the data analysed and a sample of Chi square and odd ratio analysis for pfert K76T at Cape Coast.

\section{Acknowledgements}

We are grateful to the Department of Biomedical Sciences, University of Cape Coast laboratory, and the medical staff of St. Francis Xavier hospital, and Twifo Praso district hospital for their technical support.

\section{Authors' contributions}

All authors contributed equally. All authors read and approved the final manuscript.

\section{Funding}

No funding agent.

Availability of data and materials

Not applicable.

\section{Declarations}

Ethics approval and consent to participate

Not applicable.

Consent for publication

Not applicable.

Competing interests

The authors have no competing interests to declare.

Human and animal rights

Not applicable.

Author details

${ }^{1}$ Department of Biomedical Sciences, School of Allied Health Sciences, College of Health and Allied Sciences, University of Cape Coast, Cape Coast, Ghana. 
${ }^{2}$ Department of Medical Laboratory Science, University of Cape Coast, Cape Coast, Ghana. ${ }^{3}$ Department of Biology Education, Faculty of Science Education, University of Education, Winneba, Ghana.

Received: 4 February 2021 Accepted: 15 November 2021 Published online: 25 November 2021

\section{References}

1. Dhingra SK, Gabryszewski SJ, Small-Saunders JL, Yeo T, Henrich PP Mok S, et al. Global spread of mutant pfert and its pleiotropic impact on Plasmodium falciparum multidrug resistance and fitness. mBio. 2019;10:e02731-18.

2. Lu F, Zhang M, Culleton RL, Xu S, Tang J, Zhou H, et al. Return of chloroquine sensitivity to Africa? Surveillance of African Plasmodium falciparum chloroquine resistance through malaria imported to China. Parasit Vectors. 2017:10:355.

3. Pfeiffer K, Some F, Müller O, Sie A, Kouyate B, Haefeli WE, et al. Clinical diagnosis of malaria and the risk of chloroquine self-medication in rural health centres in Burkina Faso. Trop Med Int Health. 2008;13:418-26.

4. WHO. World malaria report. 20 years of global progress and challenges. Geneva: World Health Organization; 2020. p. 2020.

5. WHO. Malaria policy advisory group (MPAG) meeting: meeting report Geneva: World Health Organization, 2021.

6. Mekonnen SK, Aseffa A, Berhe N, Teklehaymanot T, Clouse RM, Gebru T, et al. Return of chloroquine-sensitive Plasmodium falciparum parasites and emergence of chloroquine-resistant Plasmodium vivax in Ethiopia. Malar J. 2014;13:244

7. Lucchi NW, Komino F, Okoth SA, Goldman I, Onyona P, Wiegand RE, et al. In vitro and molecular surveillance for antimalarial drug resistance in Plasmodium falciparum parasites in Western Kenya reveals sustained artemisinin sensitivity and increased chloroquine sensitivity. Antimicrob Agents Chemother. 2015;59:7540-7.

8. Ofori MF, Kploanyi EE, Mensah BA, Dickson EK, Kyei-Baafour E, Gyabaa S, et al. Ex vivo sensitivity profile of Plasmodium falciparum clinical isolates to a panel of antimalarial drugs in Ghana 13 years after national policy change. Infect Drug Resist. 2021;14:267.

9. Sevene E, González R, Menéndez C. Current knowledge and challenges of antimalarial drugs for treatment and prevention in pregnancy. Expert Opin Pharmacother. 2010;11:1277-93.

10. Kamugisha E, Bujila I, Lahdo M, Pello-Esso S, Minde M, Kongola G, et al. Large differences in prevalence of pfcrt and pfmdr1 mutations between Mwanza, Tanzania and Iganga, Uganda - a reflection of differences in policies regarding withdrawal of chloroquine? Acta Trop. 2012;121:148-51.

11. Dagnogo O, Ako AB, Ouattara L, Dago ND, Coulibaly DN, Touré AO, et al. Towards a re-emergence of chloroquine sensitivity in Côte d'Ivoire? Malar J. 2018;17:413.

12. Duah NO, Matrevi SA, De Souza DK, Binnah DD, Tamakloe MM, Opoku VS, et al. Increased pfmdrl gene copy number and the decline in pfcrt and pfmdr 1 resistance alleles in Ghanaian Plasmodium falciparum isolates after the change of anti-malarial drug treatment policy. Malar J. 2013;12:377.

13. Asare KK, Boampong JN, Afoakwah R, Ameyaw EO, Sehgal R, Quashie NB. Use of proscribed chloroquine is associated with an increased risk of pfcrt T76 mutation in some parts of Ghana. Malar J. 2014;13:246.

14. Mensah BA, Aydemir O, Myers-Hansen JL, Opoku M, Hathaway NJ, Marsh PW, et al. Antimalarial drug resistance profiling of Plasmodium falciparum infections in Ghana using molecular inversion probes and next-generation sequencing. Antimicrob Agents Chemother. 2020;64:e01423-e1519.

15. Hamer DH, MacLeod WB, Addo-Yobo E, Duggan CP, Estrella B, Fawzi WW, et al. Age, temperature, and parasitaemia predict chloroquine treatment failure and anaemia in children with uncomplicated Plasmodium falciparum malaria. Trans R Soc Trop Med Hyg. 2003;97:422-8.

16. Desai M, Buff AM, Khagayi S, Byass P, Amek N, van Eijk A, et al. Agespecific malaria mortality rates in the KEMRI/CDC health and demographic surveillance system in western Kenya, 2003-2010. PLoS One. 2014;9:e106197.

17. Kayode AT, Akano K, Ajogbasile FV, Uwanibe JN, Oluniyi PE, Bankole BE, et al. Polymorphisms in Plasmodium falciparum chloroquine resistance transporter ( $p f c r t$ ) and multidrug-resistant gene 1 (pfmdr 1 ) in Nigerian children 10 years post-adoption of artemisinin-based combination treatments. Int J Parasitol. 2020;51:301-10.

18. Abugri J, Ansah F, Asante KP, Opoku CN, Amenga-Etego LA, Awandare GA. Prevalence of chloroquine and antifolate drug resistance alleles in Plasmodium falciparum clinical isolates from three areas in Ghana. AAS Open Research. 2018;1:1.

19. Asare KK. Evaluation of Plasmodium falciparum chloroquine resistant markers in selected health facilities in central region after seven years of banning chloroquine treatment in Ghana. https://ir.ucc.edu.gh/xmlui/ handle/123456789/2768.

20. Aninagyei E, Duedu KO, Rufai T, Tetteh CD, Chandi MG, Ampomah P, et al. Characterization of putative drug resistant biomarkers in Plasmodium falciparum isolated from Ghanaian blood donors. BMC Infect Dis. 2020;20:533.

21. Figueiredo P, Benchimol C, Lopes D, Bernardino L, do Rosário VE, Varandas $L$, et al. Prevalence of pfmdr1, pfcrt, pfdhfr and pfdhps mutations associated with drug resistance, in Luanda, Angola. Malar J. 2008;7:236.

22. Cerqueira GC, Cheeseman IH, Schaffner SF, Nair S, McDew-White M, Phyo AP, et al. Longitudinal genomic surveillance of Plasmodium falciparum malaria parasites reveals complex genomic architecture of emerging artemisinin resistance. Genome Biol. 2017;18:78.

23. Winzeler EA, Manary MJ. Drug resistance genomics of the antimalarial drug artemisinin. Genome Biol. 2014;15:544.

24. Arama C, Troye-Blomberg M. The path of malaria vaccine development: challenges and perspectives. J Int Med. 2014;275:456-66.

25. Parhizgar AR, Tahghighi A. Introducing new antimalarial analogues of chloroquine and amodiaquine: a narrative review. Iran J Med Sci. 2017;42:115.

26. Freeman A, Kwarteng A, Febir LG, Amenga-Etego S, Owusu-Agyei $S$, Asante KP. Two years post affordable medicines facility for malaria program: availability and prices of anti-malarial drugs in central Ghana. J Pharm Policy Pract. 2017;10:15.

27. WHO. Artemisinin and artemisinin-based combination therapy resistance: status report. Geneva: World Health Organization, 2016.

28. Haldar K, Bhattacharjee S, Safeukui I. Drug resistance in Plasmodium. Nat Rev Microbiol. 2018;16:156.

29. Matrevi SA, Opoku-Agyeman P, Quashie NB, Bruku S, Abuaku B, Koram KA, et al. Plasmodium falciparum kelch propeller polymorphisms in clinical isolates from Ghana from 2007 to 2016. Antimicrob Agents Chemother. 2019;63:e00802-e819.

30. Duah NO, Matrevi SA, Quashie NB, Abuaku B, Koram KA. Genetic diversity of Plasmodium falciparum isolates from uncomplicated malaria cases in Ghana over a decade. Parasit Vectors. 2016;9:416.

31. Asare KK, Boampong JN, Duah NO, Afoakwah R, Sehgal R, Quashie NB. Synergism between pfcrt and pfmdrl genes could account for the slow recovery of chloroquine sensitive Plasmodium falciparum strains in Ghana after chloroquine withdrawal. J Infect Public Health. 2017:10:110-9.

32. Tyagi RK, Gleeson PJ, Arnold L, Tahar R, Prieur E, Decosterd L, et al. Highlevel artemisinin-resistance with quinine co-resistance emerges in $P$. falciparum malaria under in vivo artesunate pressure. BMC Med. 2018;16:181.

33. Vydyam P, Dutta D, Sutram N, Bhattacharyya S, Bhattacharyya MK. A small-molecule inhibitor of the DNA recombinase Rad51 from Plasmodium falciparum synergizes with the antimalarial drugs artemisinin and chloroquine. J Biol Chem. 2019;294:8171-83.

34. Yadav BS, Chaturvedi N, Marina N. Recent advances in system based study for anti-malarial drug development process. Curr Pharm Des. 2019;25:3367-77.

35. Kumar S, Bhardwaj TR, Prasad DN, Singh RK. Drug targets for resistant malaria: historic to future perspectives. Biomed Pharmacother. 2018;104:8-27.

36. Rout S, Patra NP, Mahapatra RK. An in silico strategy for identification of novel drug targets against Plasmodium falciparum. Parasitol Res. 2017;116:2539-59.

37. Crowther GJ, Napuli AJ, Gilligan JH, Gagaring K, Borboa R, Francek C, et al Identification of inhibitors for putative malaria drug targets among novel antimalarial compounds. Mol Biochem Parasitol. 2011;175:21-9.

38. Hemming-Schroeder E, Umukoro E, Lo E, Fung B, Tomás-Domingo P, Zhou $\mathrm{G}$, et al. Impacts of antimalarial drugs on Plasmodium falciparum drug resistance markers, Western Kenya, 2003-2015. Am J Trop Med Hyg. 2018;98:692-9 
39. Frosch AE, Laufer MK, Mathanga DP, Takala-Harrison S, Skarbinski J, Claassen CW, et al. Return of widespread chloroquine-sensitive Plasmodium falciparum to Malawi. J Infect Dis. 2014;210:1110-4

40. Toghueo RM, Kemgne EA, Eke P, Kanko MI, Dize D, Sahal D, Boyom FF. Antiplasmodial potential and GC-MS fingerprint of endophytic fungal extracts derived from Cameroonian Annona muricata. J Ethnopharmacol. 2019;235:111-21.

41. Ojurongbe O, Ogungbamigbe TO, Fagbenro-Beyioku AF, Fendel R, Kremsner PG, Kun JF. Rapid detection of pfcrt and pfmdr 1 mutations in Plasmodium falciparum isolates by FRET and in vivo response to chloroquine among children from Osogbo, Nigeria. Malar J. 2007;6:41.

42. Mayor AG, Gómez-Olivé X, Aponte JJ, Casimiro S, Mabunda S, Dgedge M, Barreto A, Alonso PL. Prevalence of the K76T mutation in the putative Plasmodium falciparum chloroquine resistance transporter ( $p f c r t)$ gene and its relation to chloroquine resistance in Mozambique. J Infect Dis. 2001;183:1413-6.

43. Nsobya SL, Kiggundu M, Nanyunja S, Joloba M, Greenhouse B, Rosenthal PJ. In vitro sensitivities of Plasmodium falciparum to different antimalarial drugs in Uganda. Antimicrob Agents Chemother. 2010;54:1200-6.

44. Gabryszewski SJ, Dhingra SK, Combrinck JM, Lewis IA, Callaghan PS, Hassett MR, et al. Evolution of fitness cost-neutral mutant pfcrt conferring $P$. falciparum 4-aminoquinoline drug resistance is accompanied by altered parasite metabolism and digestive vacuole physiology. PLoS Pathog. 2016:12:e1005976.
45. Pelleau S, Moss EL, Dhingra SK, Volney B, Casteras J, Gabryszewski SJ, et al. Adaptive evolution of malaria parasites in French Guiana: reversal of chloroquine resistance by acquisition of a mutation in pfcrt. Proc Natl Acad Sci USA. 2015;112:11672-7.

46. Gharbi M, Flegg JA, Hubert V, Kendjo E, Metcalf JE, Bertaux L, et al. Longitudinal study assessing the return of chloroquine susceptibility of Plasmodium falciparum in isolates from travellers returning from West and Central Africa, 2000-2011. Malar J. 2013;12:35.

47. Prothero RM. Migration and malaria risk. Health, Risk Society. 2001;3:19-38.

48. Lynch C, Roper C. The transit phase of migration: circulation of malaria and its multidrug-resistant forms in Africa. PLoS Med. 2011;8:e1001040.

49. Takala-Harrison S, Laufer MK. Antimalarial drug resistance in Africa: key lessons for the future. Ann NY Acad Sci. 2015;1342:62-7.

50. Zeng W, Bai Y, Wang M, Wang Z, Deng S, Ruan Y, et al. Significant divergence in sensitivity to antimalarial drugs between neighboring Plasmodium falciparum populations along the eastern border of Myanmar. Antimicrob Agents Chemother. 2017;61:e01689-e1716.

\section{Publisher's Note}

Springer Nature remains neutral with regard to jurisdictional claims in published maps and institutional affiliations.
Ready to submit your research? Choose BMC and benefit from:

- fast, convenient online submission

- thorough peer review by experienced researchers in your field

- rapid publication on acceptance

- support for research data, including large and complex data types

- gold Open Access which fosters wider collaboration and increased citations

- maximum visibility for your research: over $100 \mathrm{M}$ website views per year

At BMC, research is always in progress.

Learn more biomedcentral.com/submissions 